explanation is correct it would mean either that life expectancy remained at the 1971-2 level or that the figures had declined to an equal extent for both men and women.

\section{The demon drink}

Whatever his lack of precision in that connection, Urlanis is certainly explicit about the chief way in which women can cherish their husbands, sons, and brothers: it is by protecting them from the harmful consequences of drinking and smoking. In listing the ills that result from the former he ranges widely, covering economic losses and social problems, in addition to diseases directly attributable to alcoholism. The catalogue runs as follows: "damage to the cardiovascular system; cirrhosis of the liver; accidents on the roads, at work, and in private life; reduced productivity of labour; absenteeism; wasted time; damage to equipment; crime; fires started by cigarette ends thrown away by drunks; the birth of defective children; and break-up of the family."

As for smoking, which he terms the younger brother of alcoholism, Urlanis notes that in recent years women-including young ones-have rushed to take up the habit. Nevertheless, men are the heavier smokers and consequently sustain greater damage to their health. Perhaps to dispel any lingering doubts on this score, the demographer reaffirms that "the connection between cancer of the lungs and cigarette smoke has been proved and now constitutes an indisputable fact."

So far in his article Dr Urlanis has not supported his statements with comparisons of disease-specific death rates for the two sexes. By the late 1970s, this information would quite probably have been classified as too "sensitive" for release to the general public. But the wisdom of any such policy may be questioned on the ground that concealment is likely to prove counterproductive, helping to foster or at least doing nothing to modify deep-seated obscurantist attitudes that discount the advice given by individuals and by health education materials.

\section{Deaths from specific causes}

It is worth noting that published figures for earlier years show a striking difference between the sexes in respect of lung cancer. In 1971-2 the death rates from carcinoma of the lungs, trachea, and bronchus stood at 46.6 per 100000 for men and 6.5 per 100000 for women. These figures are fully comparable since they were standardised on the basis of the age structure of the total population. It may be added that the standardised death rates for all forms of malignant neoplasms were 184.3 per 100000 for men and 101.9 per 100000 for women in the same years.

The only other mortality data provided by this source relate to diseases of the cardiovascular system; in 1971-2 the standardised rates were $474 \cdot 1$ per 100000 for men and $366 \cdot 3$ per 100000 for women. Within that broad grouping there was an especially pronounced disparity in respect of myocardial infarct; the standardised rates were 32.7 and 10.3 per 100000 for men and women respectively. ${ }^{2}$ All the figures cited above are for the Soviet Union as a whole and so possibly conceal important differences as between the constituent republics of the Union.

According to Urlanis, accidents represent the third major factor explaining the increase in male mortality. Without naming a year, he states that $12-14^{\circ}$ of deaths among men of all ages are accounted for by accidents, poisoning, and injuries. Among men aged 20-24 the figure rises as high as $80 \%$.

Another life-threatening influence identified by Urlanis is the combination of insufficient exercise and a diet high in calories. For loving women and good housewives he has this succinct message: "Do not overfeed your husbands and sons and ensure that their diet is a balanced one." In comment it should be said that in many parts of the Soviet Union advice about a balanced diet is not always easily followed, largely because of chronic shortages of various foodstuffs, which are compounded by the rationing system whereby State-organised supplies of food vary according to the priority rating of the town in question. (Moscow, predictably enough, is in the first category.)

\section{Compulsory health checks}

In his first article the author had advocated a specific institutional innovation; taking the existing women's consultation centres as a model, he recommended creating within the health service a network of consultation centres for men. Ten years later he remained convinced of the need for such a programme. He justified it by the argument that "the current pattern of causes of death for men over 45 years is characterised by the prevalence of chronic diseases which demand early diagnosis for their successful treatment."

Largely thanks to Soviet efforts, it is widely known in the West that routine examinations feature prominently in the Soviet health service. What we are not told-and this omission must be viewed as critical-is whether their effectiveness has been shown beyond question. So considerable interest attaches to Urlanis's comment that, owing to severe shortages of contemporary diagnostic equipment, "the prophylactic examinations involving tens of millions of people are superficial to a certain extent and latent diseases frequently remain latent."

By implication, his proposal entails pre-empting substantial amounts of skilled labour and fixed capital. Urlanis, however, does not burke this issue, emphasising that the solution of health care problems requires the establishment of priorities. Men, especially those in the defined age group, "must be given one of the first places" (along with women who work in unfavourable conditions), and "at the end of the day their priority must receive full official recognition."

While the point cannot be established for certain, it seems very probable that the USSR Health Ministry has decided not to endorse the concept of consultation centres for men. Better success may have attended Urlanis's other main recommendation, which was that the Demographic Institute of the USSR Academy of Sciences, closed some years ago, should be re-established to undertake detailed and wide-ranging investigations into the causes of death and, in particular, the causes of male mortality. In any event it seems most unlikely that figures for male life expectancy will be released again until they come closer to echoing the psalmist's time-honoured words: "The years of our life are three scere and ten."

\section{References \\ ${ }^{1}$ Urlanis B. I Snova: Beregite Muzhchin! Literaturnaya Gazeta 1978;23:11. 2 Sovetskoe Zdravookhranenie 1974;4:92, 94.}

\section{Correction}

\section{"New chronic" patients}

In the paper by Dr T H Bewley and others (31 October 1981, pp 1161-4), the final sentence of "Results" (p 1163, lines 2 and 3) should read: ". . that 27 of the new group might be discharged, and that 54 might remain as inpatients indefinitely." In the abstract the penultimate sentence (p 1161, lines 8 and 9) should end: “. . . and two-thirds of them were likely to require permanent care." 